\title{
The Effect of Initial Creep Damage on Unloading Failure Properties of Sandstone from Macro-mesoscopic Perspective
}

\author{
Yu Wang ${ }^{1,2^{*}}$, Qingning Qiao ${ }^{1}$, Jianlin $\mathrm{Li}^{1}$ \\ ${ }^{1}$ Key Laboratory of Geological Hazards on Three Gorges Reservoir Area, \\ Ministry of Education, China Three Gorges University, \\ Yichang City, Hubei Province, 443002, China \\ 2 Hubei Key Laboratory of Disaster Prevention and Mitigation, \\ China Three Gorges University, \\ Yichang City, Hubei Province, 443002, China \\ *Corresponding author, e-mail: wangyu@ctgu.edu.cn
}

Received: 10 June 2019, Accepted: 16 August 2019, Published online: 08 October 2019

\begin{abstract}
The aim of this research was to show the effect of initial creep damage on unloading failure of rock from macro-mesoscopic perspective. A series of triaxial creep tests were carried out on sandstone to simulate initial creep damage and then unloading confining pressure tests were performed, respectively. A creep damage variable was proposed to analyze the degree of initial creep damage and the relationship of it with the macroscopic strength parameters was established. The results showed that the unloading amount of confining pressure and residual strength all tend to decrease when the degree of initial creep damage increases. The critical challenge was how to describe the effect of initial creep damage from mesoscopic perspective. This aim was achieved through two steps. In the first step, the mesoscopic properties were analyzed using experimentally obtained SEM images of the rock samples with different levels of initial creep damage. By comparative analysis of porosities in different magnifications, it can be concluded that porosity can't reflect the effect of initial creep damage very well, thus, other pore parameters are further proposed. In the second step, three pore parameters were calculated by using the Matlab and IPP software, then, the average value of mean pore diameter is determined as the proper evaluation parameter and, finally, the agreement was verified between the mesoscopic pore parameter and creep damage variable.
\end{abstract}

Keywords

initial creep damage, unloading, macroscopic mechanical parameters, mesoscopic structure

\section{Introduction}

Creep is an important, time-dependent mechanical behavior of rock and usually leads to different levels of damage or even failure. Consequently, the creep behavior of various rocks has been widely discussed on the basis of numerical simulation, laboratory tests and field investigations [1-3]. Fan et al. [4] focused on the effects of confining pressure and creep parameters of oiliness mudstone and analyzed other time-dependent behaviors. Yang et al. [5] analyzes the impact of different parameters in Burgers constitutive model based on the PFC ${ }^{3 \mathrm{D}}$ [6]. Zhu et al. [7] study on the quantitative description of the evolution of creep coefficient with both soil density and soil structure under uniaxial compression. Others have studied creep in combination with other factors [8-10].
With the rapid development of rock engineering projects, such as tunnels, slopes, dams and caverns, massive rock excavations are inevitable and many researchers have noted a significant unloading effect after rock excavation and have conducted relevant analysis [11-15]. However, the previous studies primarily focused on the intact rock and paid little attention to the unloading behavior with initial creep damage. Therefore, a good understanding of the unloading behavior of rock mass with different creep damage levels is essential for stability analysis of the slope or dam foundation.

In the previous studies, a large proportion of them focused on macroscopic mechanical properties [15-19], but the application of new technologies, such as scanning electron 
microscopy (SEM), acoustic emissions (AE), nuclear magnetic resonance (NMR), has provided a powerful tool to investigate the microstructural properties of rocks. For example, Bennett et al. [20] used ion beam milling, SEM and energy dispersive X-ray spectroscopy to set simulations, which can provide a means of extracting plastic material parameters from the nanoindentation measurements and reveal the capabilities as well as limitations of an isotropic model in capturing the response of an inherently anisotropic material. Li et al. [21] studied on the relationship between loading-unloading cycle and $\mathrm{AE}$ to provide a more efficient method for issuing early warnings for dynamic rock disasters. Weng et al. [22] used a NMR technique to evaluate the degradation process under unconfined compression. Chen et al. [23] found a fact that cycling the stress transiently increases the strain rate and the rate of AE activity, but new micro-cracks do not developed by a series of uniaxial compression tests and conventional creep tests, which shows that stress perturbations commonly occurred during mining practices may promote the failure of the pillars and/or surrounding rock in active mines.

In the present research, the effect of initial creep damage on unloading behavior of rock was investigated. First, the creep experiments of sandstone were conducted to simulate different levels of initial creep damage. Then, the unloading confining pressure tests were performed on rocks with different initial creep damage levels. Finally, the creep damage variable was calculated based on damage mechanics, the unloading failure properties were analyzed and characteristic parameters were obtained from macroscopic and mesoscopic perspective, and the connection between macroscopic and mesoscopic mechanism on sandstone failure was established.

\section{Experimental materials}

Sandstone, a kind of extremely common rock in Southwest China, was taken from the bank slope of Three Gorges Reservoir. In order to reduce the dispersion of samples and avoid the differences of samples in the composition and structure, the samples as research objects were selected from the same rock mass with better integrity and homogeneity. Therefore, the differences of chemical composition and density of the samples were negligible. After polishing and cutting, the samples were processed into cylinder with $50 \mathrm{~mm}$ in diameters and $100 \mathrm{~mm}$ in height according to the International Society for Rock Mechanics (ISRM) [24], shown in Fig. 1. The sandstone was an off-white fine-grained rock material with an average dry density of $2.54 \mathrm{~g} / \mathrm{cm}^{3}$ and a Poisson's ratio of 0.41 , other mechanical parameters were shown in Table 1. It is worth noting that all the parameters in Table 1 were obtained by taking the average of the results of multiple tests. Thin section of specimens was prepared for X-ray diffraction (XRD), and the results are shown in Fig. 2. The sandstone is mainly composed of quartz and calcite and contains a small amount of dolomite, microcline intermediate, albite, and so on.

\section{Macro-mechanical tests}

\subsection{Triaxial compression creep test}

Triaxial compression creep test was carried out on typical sandstone from Three Gorges Reservoir Area using RLW2000 creep test machine (Fig. 3), and the laboratory should maintain constant temperature and humidity in the process. In the method of one-step axial pressure creep test,
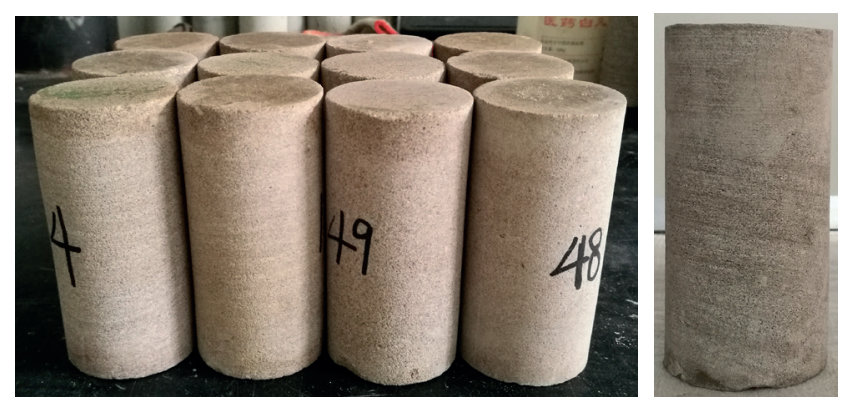

Fig. 1 Sandstone samples

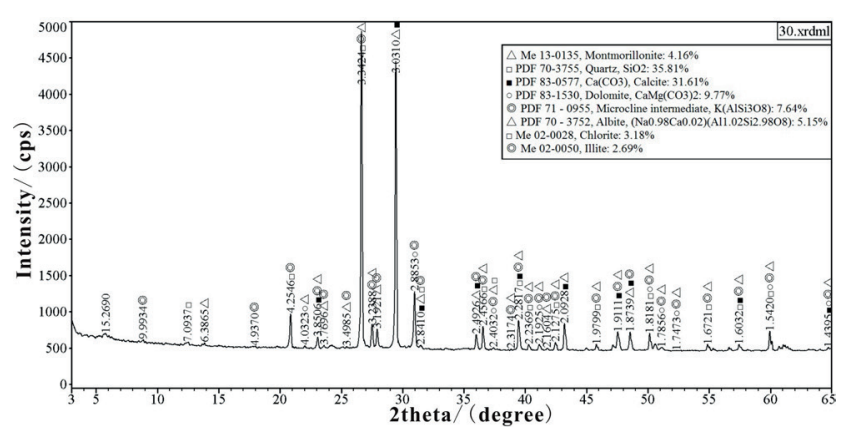

Fig. 2 Mineral components through X-ray diffraction (XRD)

Table 1 Physical-mechanical properties of sandstone

\begin{tabular}{|c|c|c|c|c|c|c|}
\hline Sample status & $\begin{array}{l}\text { Dry density } \\
\qquad /\left(\mathrm{g} \cdot \mathrm{cm}^{-3}\right)\end{array}$ & $\begin{array}{l}\text { Longitudinal wave } \\
\text { velocity } /\left(\mathrm{m} \cdot \mathrm{s}^{-1}\right)\end{array}$ & $\begin{array}{l}\text { Poisson's } \\
\text { ratio }\end{array}$ & $\begin{array}{c}\text { Elasticity } \\
\text { modulus/GPa }\end{array}$ & $\begin{array}{l}\text { Uniaxial compression } \\
\text { strength } / \mathrm{MPa}\end{array}$ & $\begin{array}{c}\text { Triaxial compression stress } \\
\text { (confining pressure is } 12 \mathrm{MPa} \text { ) } / \mathrm{MPa}\end{array}$ \\
\hline dry & 2.54 & 2044 & 0.41 & 11.77 & 39.39 & 121.31 \\
\hline
\end{tabular}




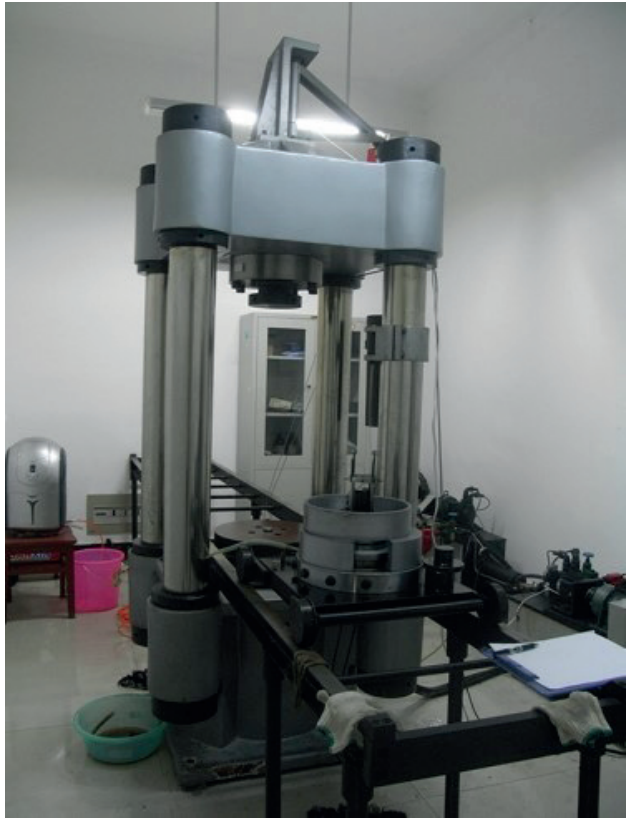

Fig. 3 RLW-2000 creep test machine

the confining pressure should be maintained at constant $12 \mathrm{MPa}$, while the axial creep stress $\sigma_{1}$ was maintained at the planned value, including 36, 48, 60, 72 and $84 \mathrm{MPa}$. The axial, confining stress state should be maintained unchanged till the creep strain rate reached constant stage, then the axial, confining pressures were removed from samples.

Triaxial one-level compression creep test curves of different sandstone samples are shown in Fig. 4. Under the effect of long-term loads, only decay creep and steady creep are reflected from strain-time curves which indicates the axial loading from $36 \mathrm{MPa}$ to $84 \mathrm{MPa}$ cannot lead to the accelerating creep. With the increase of axial pressure, creep deformations represented by decay creep and steady creep increases accordingly, shown in Table 2. In particular, creep strain rate gradually tends to a constant value as time goes by.

\subsection{Triaxial unloading confining pressure test}

Because the excavation response of a bank slope is associated with the stress path of rocks, unloading conditions often exist due to excavation-induced stress redistribution. In this study, triaxial unloading confining pressure test of creep damage specimens was conducted to resemble unloading situations of excavation on the RMT-150C system. The maximum axial load and horizontal load are up to $1000 \mathrm{kN}$ and $500 \mathrm{kN}$ separately while the maximum confining pressure can be up to $50 \mathrm{MPa}$. The stress-strain curves were obtained by extensometers during uniaxial and triaxial tests.

As shown in Table 2, the specimens were one testing group with different initial creep damage levels. The unloading point for the confining pressure in the triaxial unloading tests was set as $84 \mathrm{MPa}$, which is $70 \%$ of the triaxial strength, and the axial loading method was changed from displacement control to loading control at the unloading point, the initial confining pressures were $12 \mathrm{MPa}$, respectively. The complete stress-strain curves and corres-

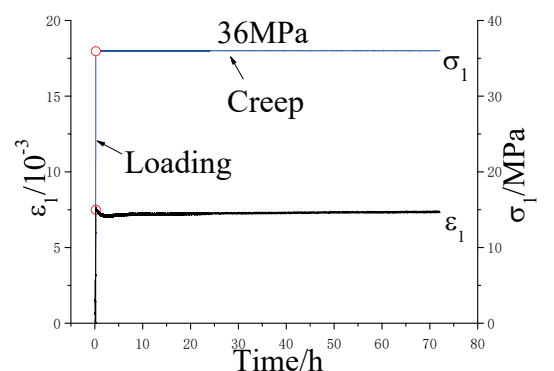

(a) A-82

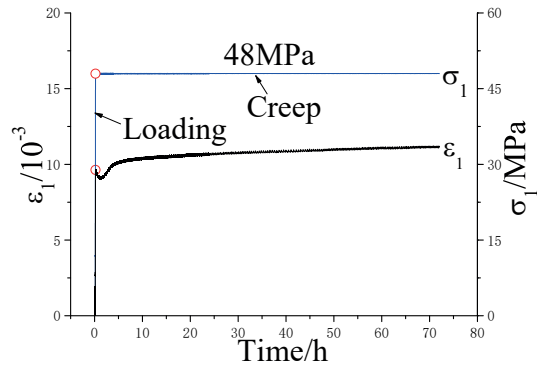

(b) A-23

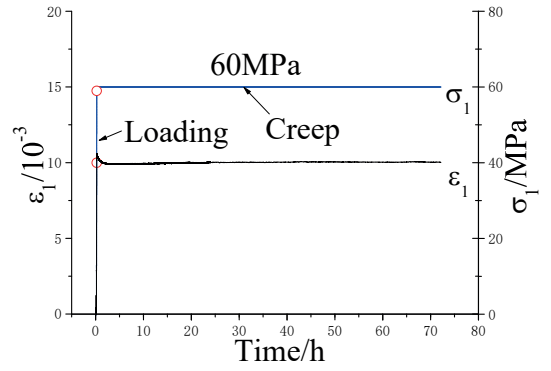

(c) A-30

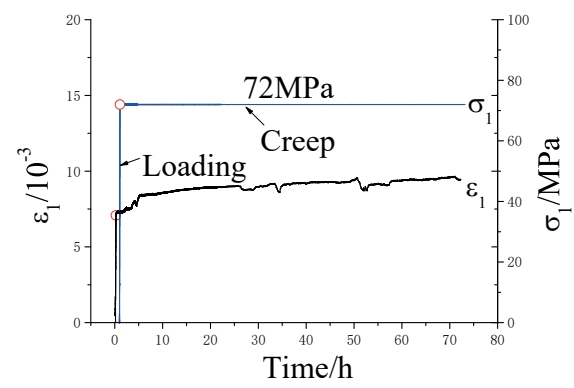

(d)A-25

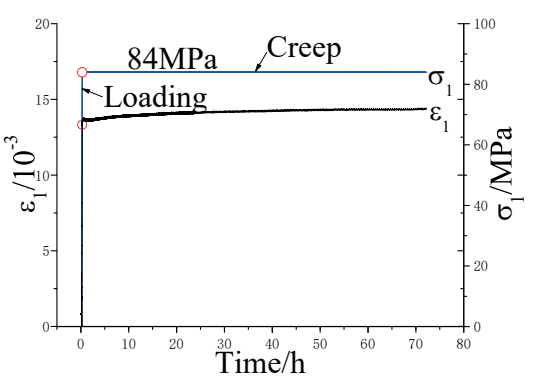

(e) A-27

Fig. 4 Strain-stress-time curves for sandstone under different axial creep stress $\sigma_{1}$ 
Table 2 Creep strain values in different stage

\begin{tabular}{|c|c|c|c|c|c|c|c|}
\hline \multirow{2}{*}{$\begin{array}{l}\text { Specimen } \\
\text { number }\end{array}$} & \multirow{2}{*}{$\begin{array}{c}\text { Axial creep } \\
\text { stress } \sigma_{1} / \mathrm{MPa}\end{array}$} & \multicolumn{2}{|c|}{ Decay creep strain $\varepsilon / 10^{-6}$} & \multicolumn{2}{|c|}{ Steady creep strain $\varepsilon / 10^{-6}$} & \multicolumn{2}{|c|}{ Average value of creep rate $/ 10^{-5} \cdot \mathrm{h}^{-1}$} \\
\hline & & Axial & Lateral & Axial & Lateral & Axial & Lateral \\
\hline A-82 & 36 & 370 & 1319 & 92.6 & 2229 & 0.16 & 3.27 \\
\hline A-23 & 48 & 379 & 167 & 129 & 218 & 0.19 & 0.31 \\
\hline A-30 & 60 & 435 & 570 & 602 & 921 & 0.87 & 1.31 \\
\hline A-25 & 72 & 462 & 649 & 1500 & 962 & 2.16 & 1.37 \\
\hline A-27 & 84 & 574 & 768 & 1936 & 1283 & 2.92 & 1.83 \\
\hline
\end{tabular}

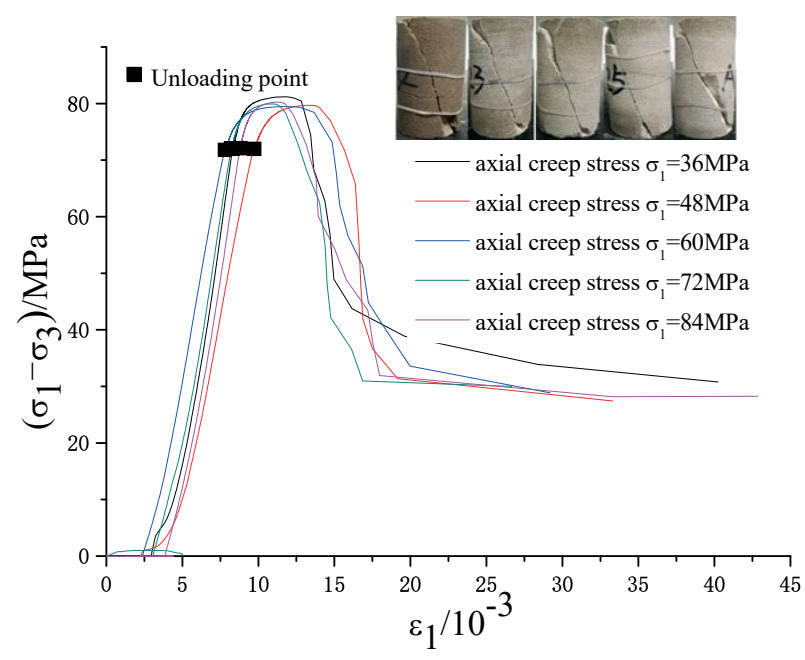

Fig. 5 Strain-stress curves for specimens with different levels of creep damage

ponding failure mode of specimens are shown in Fig. 5. The similar failure mode, shear mode, was observed in different creep damage samples, whereas the variations of the strain-stress relations in linear elastic, unloading and failure stages are related to the initial creep damage degree of sandstone.

\section{Creep damage variable calculation}

The damage variable, based on the effective stress concept, represents average material degradation, which reflects the various types of damage at the meso-scale level like nucleation and growth of voids, cracks, cavities, microcracks and other mesoscopic defects [25]. In this study, a creep damage variable was defined in terms of the elastic modulus of the material [26-27]. Then, the macro description of creep damage accumulation (D) can be expressed by a scalar equation as follows (Eq. (1)):

$$
D=1-\frac{\bar{E}}{E}
$$

where $E$ is elastic modulus of undamaged sandstone, and $\bar{E}$ is elasticity modulus of creep damage sandstone. That is $E$ represents the average slope of creep curve during linear elastic stage, shown in Fig. 6(a), and $\bar{E}$ is the average slope of unloading failure curve during linear elastic stage, shown in Fig. 6(b), and the calculated values of $E, \bar{E}$ and $D$ are given in Table 3 .

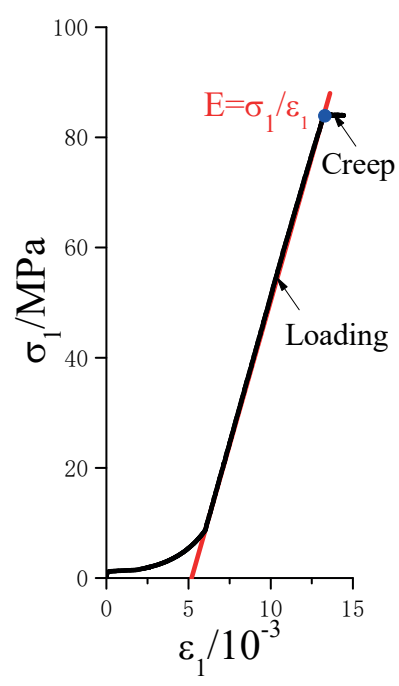

(a)

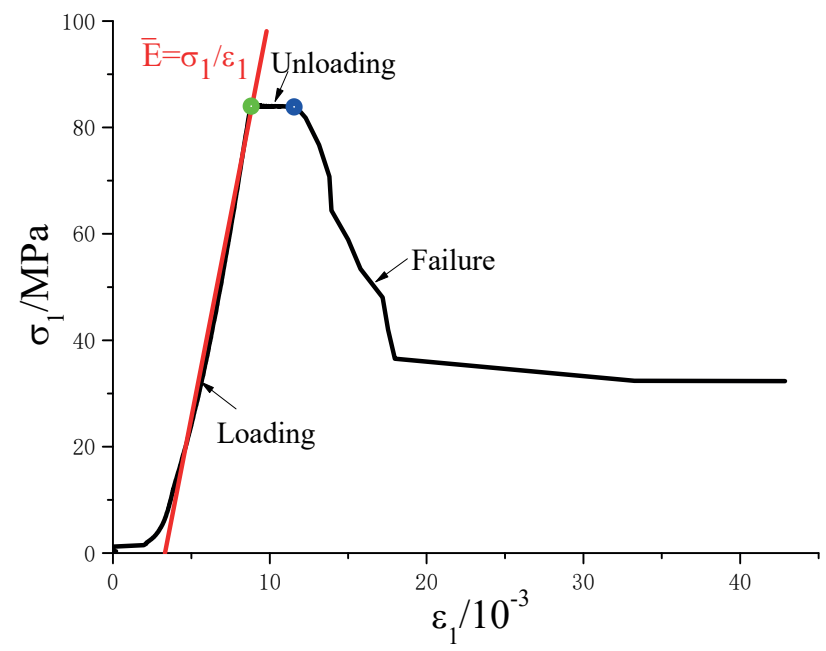

(b)

Fig. 6 Diagrams of elastic modulus. (a) initial elastic modulus E; (b) elasticity modulus after creep damage (The blue point is creep point in (a), the green point and blue point are unloading point and failure point respectively in (b)) 
Table 3 The results of $E, \bar{E}$ and $D$ of samples

\begin{tabular}{lccccc}
\hline $\begin{array}{l}\text { Axial creep stress } \sigma_{1} / \mathrm{MPa} \\
\text { Elastic modulus/GPa }\end{array}$ & 36 & 48 & 60 & 72 & 84 \\
\hline$E$ & 12.52 & 12.49 & 11.88 & 12.37 & 12.38 \\
$\bar{E}$ & 14.1 & 13.59 & 10.18 & 10.12 & 9.57 \\
$D$ & -0.13 & -0.09 & 0.14 & 0.18 & 0.22 \\
\hline
\end{tabular}

It can be seen from Table 3 that the creep damage variable increases, changed from negative to positive, with the axial creep stress increasing. Based on previous studies and the test results of this study, this paper proposed the concepts of positive and negative damage to explain the phenomenon above. The positive damage is defined that the microcracks and micropores are extended under creep loading while the negative damage is used to explain the phenomenon that microcracks and micropores are closed under creep loading. Thus, we speculated that the microcracks and micro-pores compact under low axial creep stress, while, with the axial creep stress increasing, the microcracks and micropores are extending and connecting until the macroscopic cracks appear.

\section{Law between macro-mechanical parameters and creep damage variable}

Based on the test results of Fig. 5, all related strength parameters are collected, calculated and listed in Table 4. It is obviously that the residual strength basically decreases with the increase of axial creep stress loaded on samples in creep stage.

However, the unloading amount of confining pressure present the approximate values. In order to reflect the influence of creep damage on strength parameters, parameter values of unloading amount for confining pressure and residual strength are normalized, namely,

$\Delta \bar{\sigma}_{3}=\frac{\Delta \sigma_{3}}{\sigma_{1}}$, $\bar{\sigma}_{r}=\frac{\sigma_{r}}{\sigma_{1}}$.

A law between strength parameters and creep damage variable changed with axial creep stress are obtained and shown in Figs. 7 and 8. As can be observed, when the axial creep stress increases from $36 \mathrm{MPa}$ to $84 \mathrm{MPa}$, the normalized unloading amount for confining pressure and residual strength decrease from 0.24 and 0.98 to 0.08 and 0.34 , respectively. Meanwhile, with the increase of the axial creep stress, the creep damage variable increases, which indicates that the creep damage degree is mainly determined by the creep loads, because micro-cracks and micro-pores develops with the axial creep stress, resulting in quicker and more thorough failure of sandstone in the unloading condition. In addition, the normalized unloading amount for confining pressure changes slightly and the average slope of the linear fitting curve is only -0.003 , while the normalized residual strength changes with axial creep stress is tremendous and the average slope of the linear fitting curve is -0.012 .

The results show that creep damage has a more significant effect on the residual strength of sandstone, in other word, the creep damage is higher, the possibility of complete failure for samples is higher.

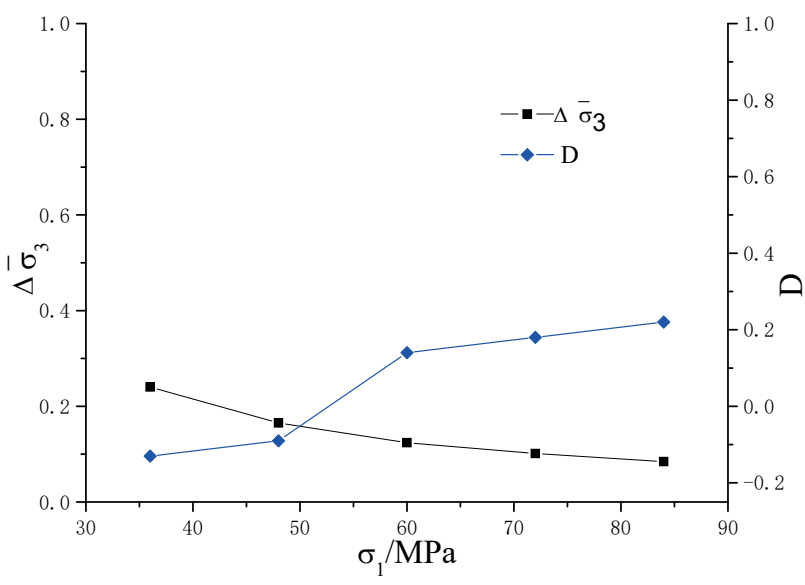

Fig. 7 Curves of $\Delta \overline{\sigma_{3}}$ and $D$

Table 4 Strength parameters of creep damage specimens

\begin{tabular}{lcccc}
\hline Sample number & Axial creep stress $\sigma_{1} / \mathrm{MPa}$ & $\begin{array}{c}\text { Axial stress at unloading } \\
\text { point } \sigma_{1} / \mathrm{MPa}\end{array}$ & $\begin{array}{c}\text { Unloading amount } \\
\text { of confining pressure } \\
\Delta \sigma_{3} / \mathrm{MPa}\end{array}$ & $\begin{array}{c}\text { Residual strength } \\
\sigma_{\mathrm{r}} / \mathrm{MPa}\end{array}$ \\
\hline A-82 & 36 & 86.48 & 8.65 & 35.17 \\
A-23 & 48 & 85.42 & 7.93 & 31.92 \\
A-30 & 60 & 86.20 & 7.44 & 34.39 \\
A-25 & 72 & 86.23 & 7.28 & 31.69 \\
A-27 & 84 & 85.74 & 7.10 & 28.73 \\
\hline
\end{tabular}




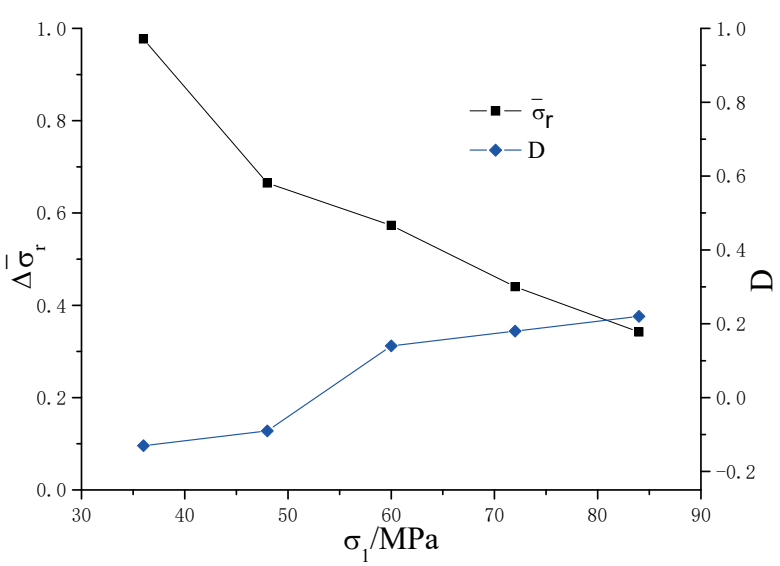

Fig. 8 Curves of $\bar{\sigma}_{r}$ and $D$

6 Failure surface mesoscopic structure of creep damage sandstone

\subsection{Qualitative analysis}

A petrographic image analysis combined with qualitative microscopy can provide more reliable results for the study of rock mechanics [28]. In order to analyze the effect of creep damage on the crack and pore propagation and fracture of rock under unloading condition, the microscopic tests of typical fractures for all sandstone specimens were carried out through a SEM combined with an energy dispersive spectrometer (EDS) at Geological and Environmental Institute of China University of Geosciences (Wuhan). Hundreds of rock fracture images of different magnifications were acquired and some representative images were chosen to illustrate the features of rock fracture with different creep damages, as shown in Figs. 9 and 10.

As we can see from Fig. 9(a), the fracture surface is rough and has a mass of pores and cracks, and the amounts of pores and cracks obviously increase in Fig. 10(a). The middle part of Fig. 9(b) shows a crack size about 17 42 $\mu \mathrm{m}$, the upper and lower right corner of Fig. 9(c) about 3 7 $\mu \mathrm{m}$, and the lower right part of Fig. 10(b) about $7 \mu \mathrm{m}$, respectively. Meanwhile, the middle part of Fig. 9(c) occurs a pore with a diameter about $80 \mu \mathrm{m}$, which is similar to the situation in Fig. 10(c). Furthermore, there are obvious slip scratches, many clay particles and detritus left behind by shear friction in Fig. 9(b, c), which is similar to Fig. 10(b, c).

In addition, the X-ray signal count detected by EDS can reflect the composition of element content [29]. Fig. 9(d)10 (d) depict the variation of the element in the orange rectangular frame of Fig. 9(c)-10(c), it can be seen that the element change is relatively small for different samples in different fields. The main elements found in the selected spots are $\mathrm{Si}$ and $\mathrm{Ca}$, so the mineral particles mainly consist of quartz and calcite, which is in accordance with Fig. 2.

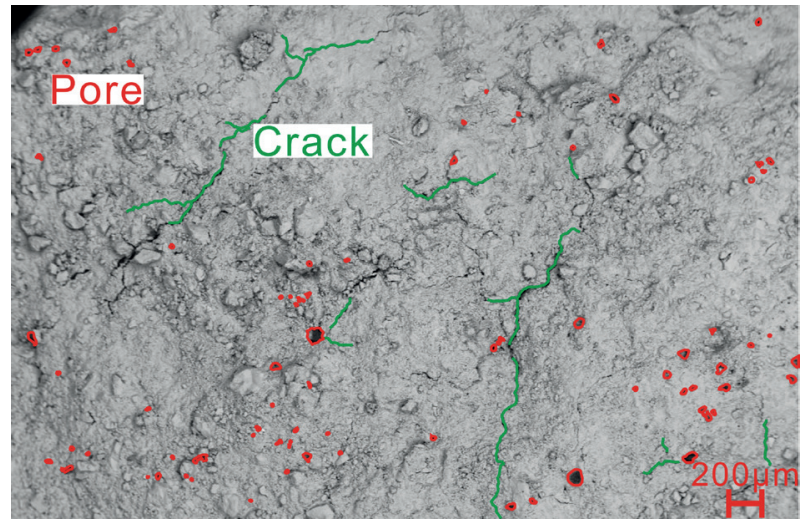

(a)

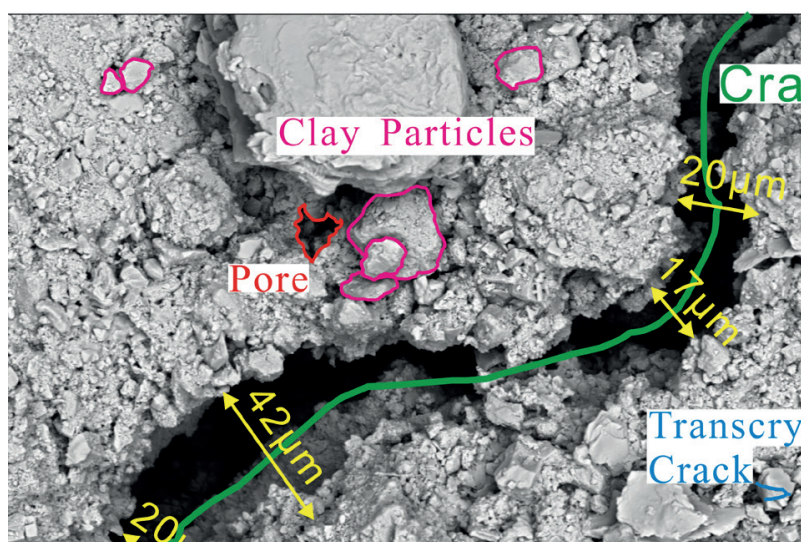

(b)

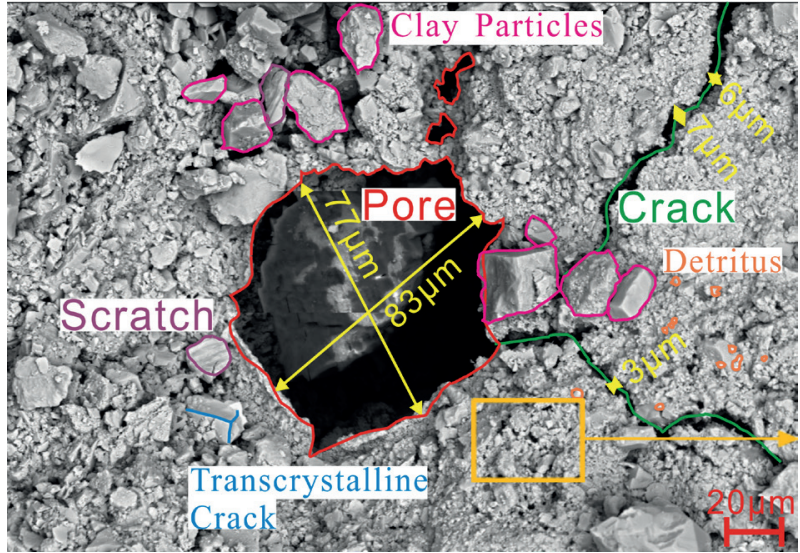

(c)

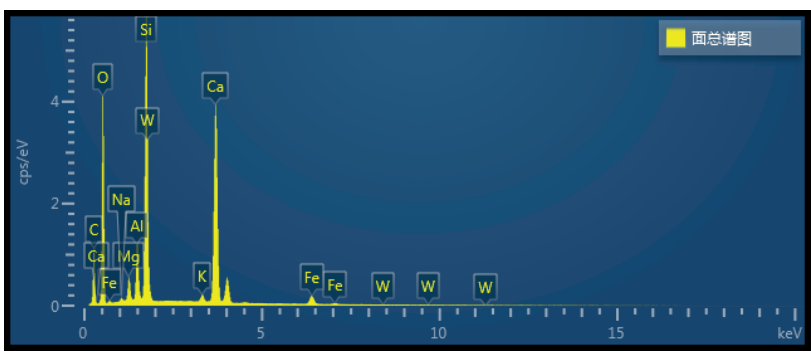

(d)

Fig. 9 Micro-morphology of sandstone fracture of A-30: (a) 25 times magnification; (b) crack size; (c) pore size; (d) EDS spectrum of the spot shown in (c) 


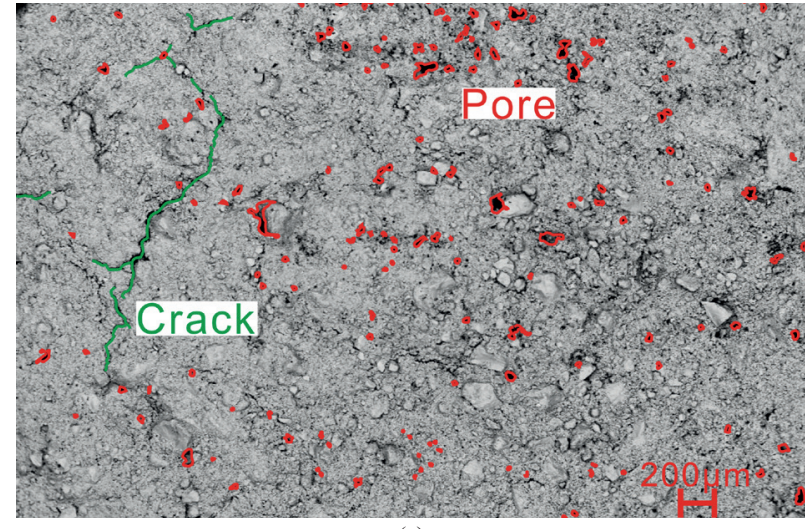

(a)

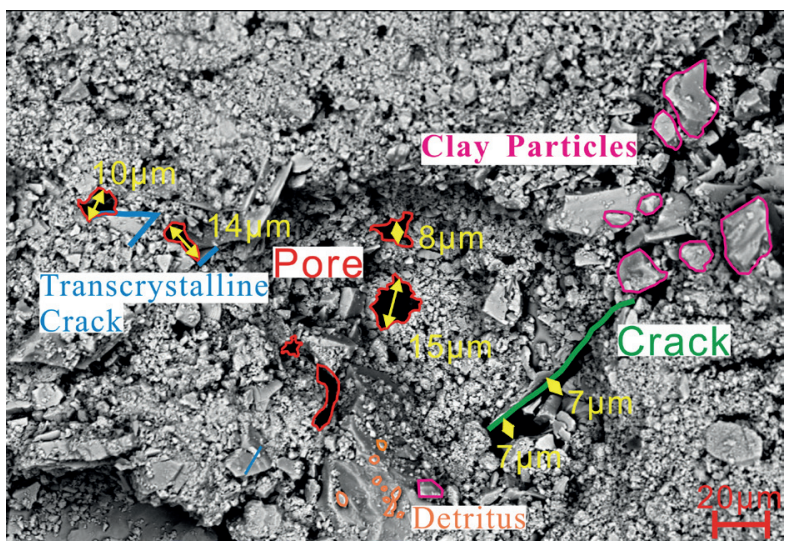

(b)

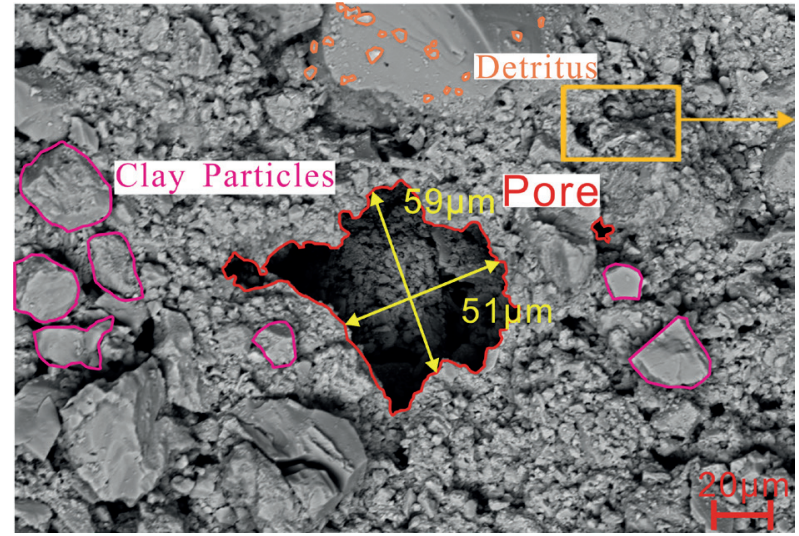

(c)

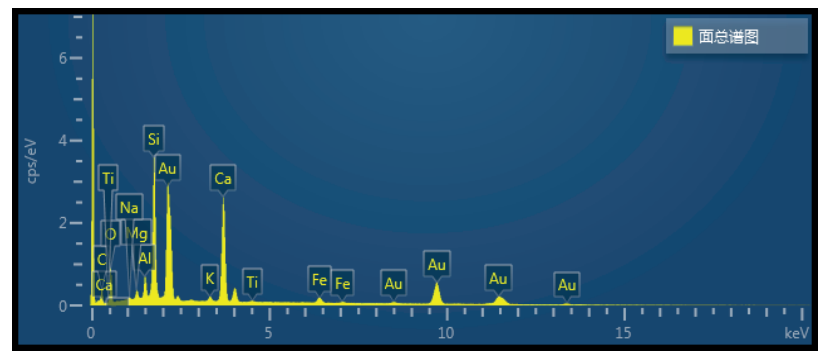

(d)

Fig. 10 Micro-morphology of sandstone fracture of A-27: (a) 25 times magnification; (b)crack size; (c) pore size; (d) EDS spectrum in the field shown in (c)
Based on the homogeneity of rock samples, we can speculate that the features of failure surface are vastly impacted by the development of pore expansion and micro-extension cracks in creep stage.

\subsection{Quantitative analysis}

Based on SEM images (Fig. 11(a)) the rock failure surface structure, including both cracks and pores, were analyzed using the Matlab software. We firstly convert the scanning electron microscope image into a binary image, and the image binarization then required setting the gray value of pixels on the image to 0 or 255 . The entire image binarization presents a clear black-and-white effect, and in order to practically display the internal structure of the image to the greatest extent, the optimal threshold is determined by the Otsu method [30] through the gray histogram (Fig. 11(b)). Corresponding to the reservoir sandstone image, the point where the pixel is 0 is black, and represents the crack and pore area. The point where the pixel is 255 is white, and represents the particle. First, the SEM image is binarized by the built-in application 'Graythresh Thresholder' in Matlab (Fig. 11(c)). Most of the crack and pore recognition results are relatively good, but sometimes, there is noise generated during the image binarization process, such as many fine tiny pores or cracks, some smaller pores merged into larger pores, which is normally the main error of the experiment. Thus, the threshold value of pixel area (the green point in Fig. 11(d)) is determined by the relationship curves between pixel area and pore number, and the 'impixelregion' in Matlab is used to check the rationality of value. Then the object will be converted to the opposite object when its pixel area is less than the threshold value, and the binary-optimized image(Fig. 11(e)) is obtained by the built-in application 'bwareaopen' in Matlab.

Conventional structure analysis is commonly used to analyze matrix porosity, and the function 'size' in Matlab can identify and extract the pixels in the binary-optimized image. Through the built-in function 'bwarea', the total

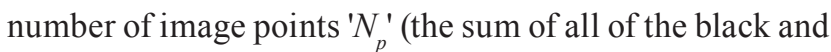
white pixels) can be obtained, respectively. Meanwhile, the pixels of pores and cracks ' $N$ ' can also be identified by function 'size'. So, porosity ' $P$ ' is the ratio of black pixels to the total pixels:

$P=\frac{N_{a}}{N_{p}} \times 100 \%$. 


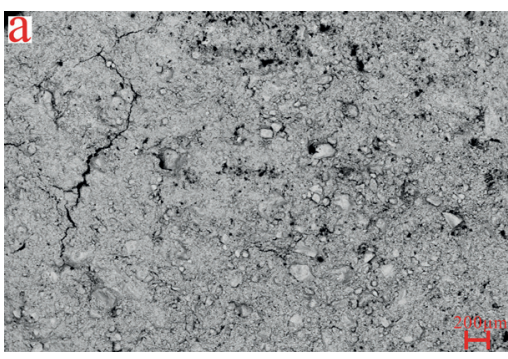

(a) SEM image

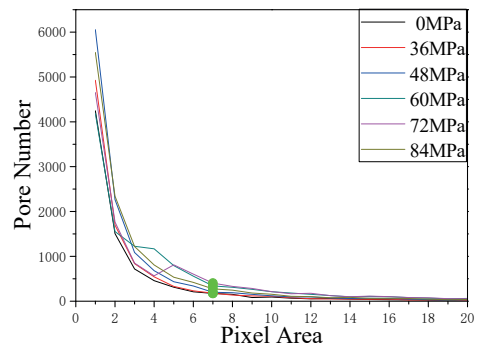

(d) curves between pixel area and pore number

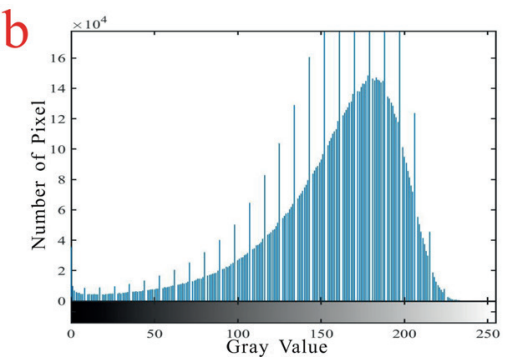

(b) gray histogram

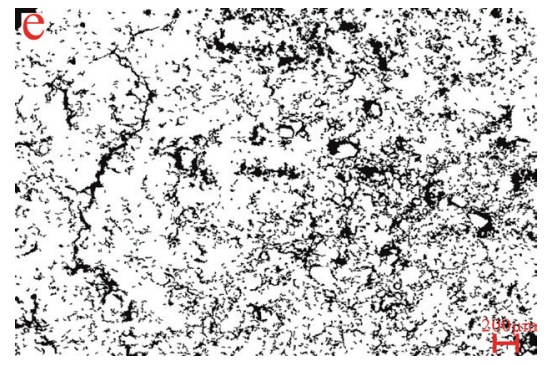

(e) binary-optimized image

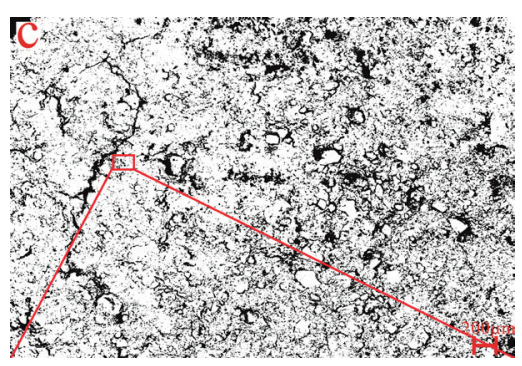

(c) binary image

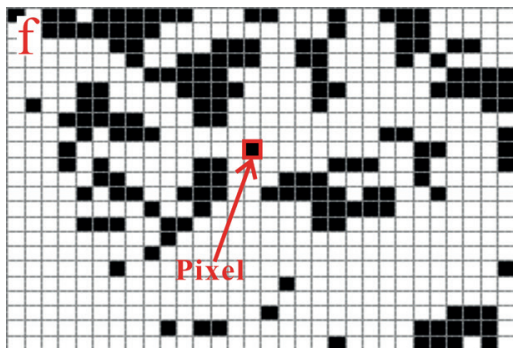

(f) pixel information about the field in (c) through 'impixelregion'

Fig. 11 The process for SEM image

In order to get the statistic features of structural characteristic parameters, three SEM images of each sample were selected and processed to binary-optimized images for magnification $\mathrm{x} 100, \mathrm{x} 400$, x800 and x1600 respectively. Based on the quantitative calculation by Matlab, Fig. 12 shows the relationship between the porosity and the axial creep stress in different magnifications. The porosity mainly decreases with the axial creep stress lower than $48 \mathrm{MPa}$, while fluctuates with the axial creep stress larger than $48 \mathrm{MPa}$, which can't reflect the variation law of creep damage very well. Besides, the porosities of three SEM images in same axial creep stress greatly differ along with the increase in magnification, which is unsuitable to describe the effect of creep damage on the failure surface.

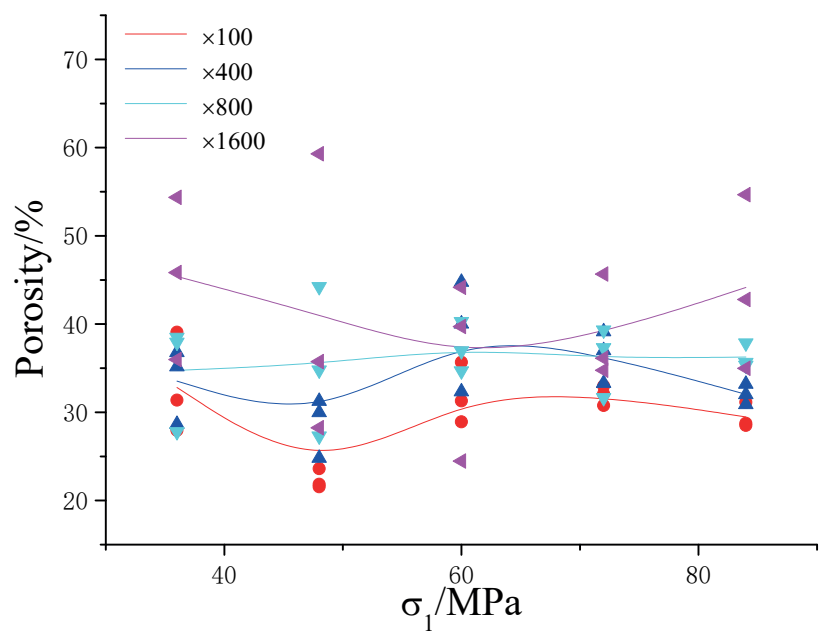

Fig. 12 Porosity versus axial creep stress curves
Miao [31] selected parameters, such as area, diameter and so on, to quantitatively analyze particles and pores by Matlab. Jiu et al. [32] use Matlab to analyze the relation between porosity, the average pore radius, the average pore throat coordination number and the median pore throat radius. In this paper, parameters related to the pore are chosen, namely, pore number $N$, maximum pore area Am, and average value of mean pore diameter $\bar{D}$.

Firstly, the pore number is counted according to the ratio of maximum diameter to minimum diameter, which means the crack is excluded when its ratio is larger than 10 . Then the maximum pore area $A_{m}$ are further calculated as Eq. (5). $A_{i}=\frac{n m}{a}, \quad i=1,2, \ldots, N$,

where $A_{i}$ is the area of $i$-th pore, $n$ is the number of pixels, $m$ is conversion unit, a is the side length of pixel point and $N$ is the pore number. Thus, the maximum pore area is determined

$A_{m}=\max \left(A_{i}\right)$.

The function 'size' in Matlab can calculate the pore diameter, but lead to larger deviation for irregular pore. In order to determine the diameter of each pore accurately, the new method in IPP software is adopted [33], which defined the gravity center as the center of pore, and calculated the pore diameter di every 2 degree, then the mean diameter $D$ of each pore is calculated

$D=\sum_{i=1}^{180} d i$. 
Combined with Eq. (7), the average value of mean diameter $\mathrm{D}$ of all pores is

$\bar{D}=\left(\sum_{i=1}^{N} D\right) / N$.

Where $N$ is the pore number. Finally, the distribution of three parameters in relation to the axial creep stress for the three images of each sample is plotted in Fig. 13, which shows the influence of axial creep stress on the pore number, maximum pore area, average value of mean pore diameters, respectively. In different magnifications, the distribution changes a lot with regard to the pore number and maximum pore area, but comparatively less in terms of the average value of mean pore diameter. Also, it is obviously that the pore number and maximum pore area drastically fluctuate along with the increase in axial creep stress, while the average value of mean pore diameters slightly increases in different magnification. And in 100 times magnification, it is easily found that the value of three pore parameters is larger than that in other magnification, which has negative impact on reflecting the relationship between the pore parameters and axial creep stress. In order to study the rule of pore parameters and creep damage variable properly, the data from the image of 100 times magnification are removed and the average value of mean pore diameter is selected as the final evaluation parameter in the subsequent analysis.

According to the statistic results of three images, the modified pore number is

$\tilde{N}=\frac{1}{3}\left(N_{1}+N_{2}+N_{3}\right)$,

where $N_{1}, N_{2}$ and $N_{3}$ are respectively the pore number of three SEM images. Combined with Eq. (8), the modified average value of mean pore diameters is

$\tilde{D}=\frac{N_{1} \bar{D}_{1}+N_{2} \bar{D}_{2}+N_{3} \bar{D}_{3}}{N_{1}+N_{2}+N_{3}}$,

where $D_{1}, D_{2}$ and $D_{3}$ are the average value of mean pore diameters for three SEM images, respectively. The variation law of the modified average value of mean pore diameters and the creep damage variable with axial creep stress are presented in Fig. 14.

It can be seen that the variation law is basically the same as the creep damage variable, that is to say, with the increase of creep damage degree, the modified average value of mean pore diameter increases relevantly. Combined with the analysis results in Section 5, this indicates that degree of creep damage of sandstone is increased

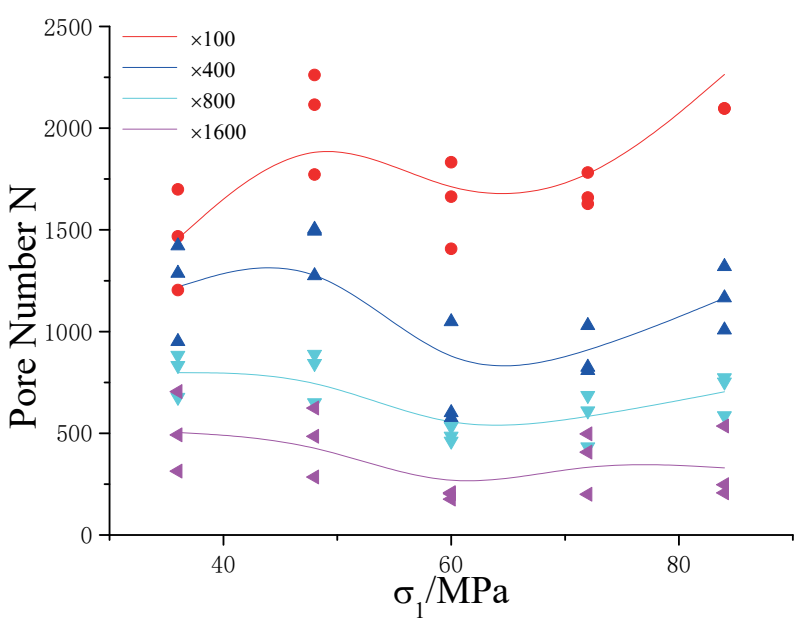

(a) Pore Number

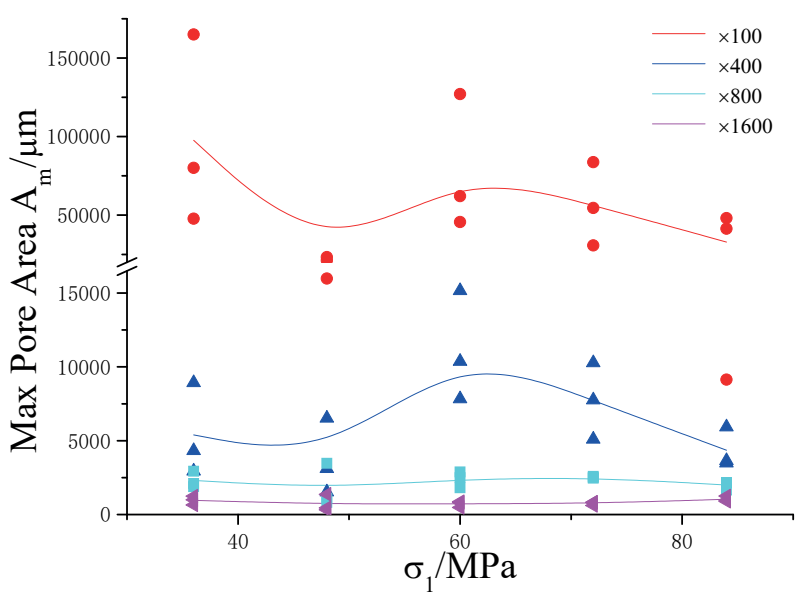

(b) Max Pore Area

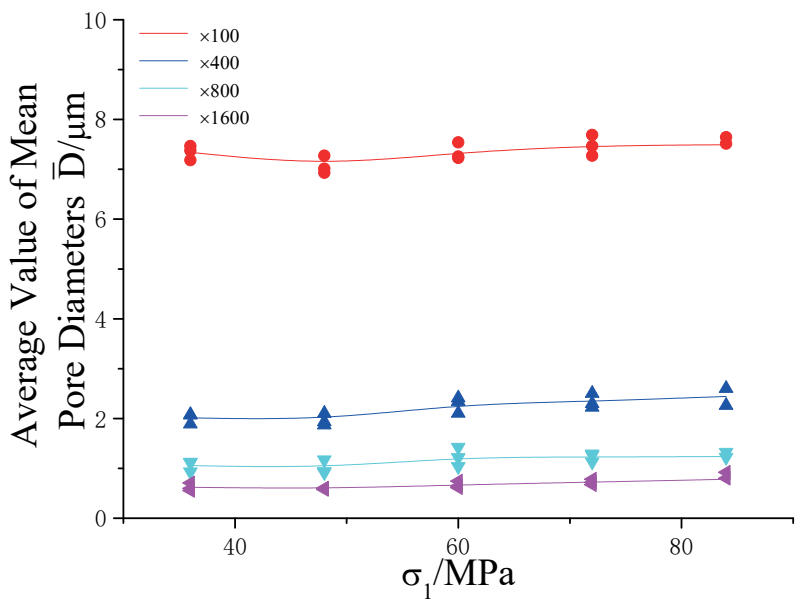

(c) Average Value of Mean Pore Diameter

Fig. 13 The relationship between pore parameters and axial creep stress $\sigma_{1}$

with the increasing axial creep stress, which worsens the structure, lowers the strength, and is attributed to the failure of rock samples. Meanwhile, this also proves that it is important and reasonable considering the impact of creep damage on unloading failure characteristics. 


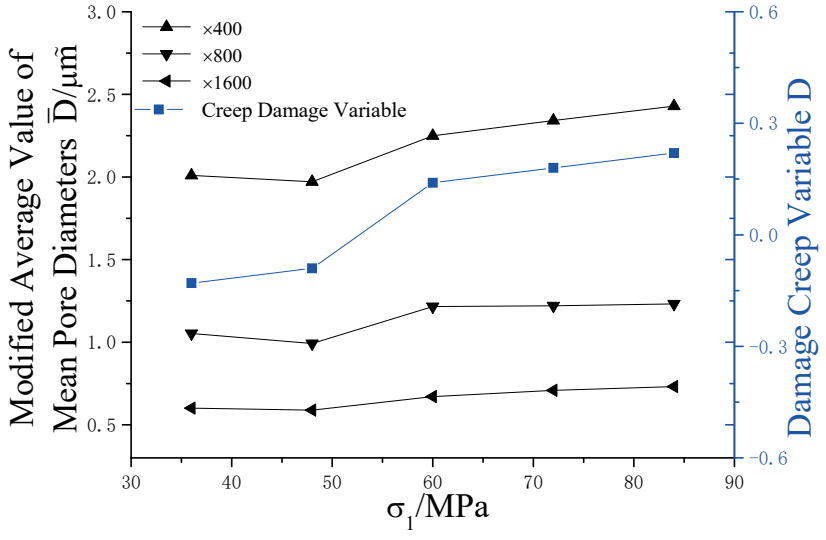

Fig. 14 Comparison results between modified average value of mean pore diameters and creep damage variable

\section{Conclusions}

The purpose of this research was to analyze the unloading failure properties of sandstone with different initial creep damage levels from macro and mesoscopic aspects. The triaxial creep tests were carried out to simulate creep damage and corresponding unloading confining pressure tests were conducted. Then, the relationship between creep damage variable and macro-mesoscopic parameters was established. The main conclusions are as follows:

1. The creep damage variable is proposed to confirm the degree of creep damage by using elasticity modulus method. The results show that the creep damage changes from negative to positive with the increase of axial creep stress, which indicates that the mesocracks and pores compact under lower axial creep stress, while extend and connect with the increase of axial creep stress.

\section{References}

[1] Zhang, X., Jiang, Y., Wang, G., Li, T. "Creep simulation test of rock based on particle discrete element method", Journal of Central South University, 46(10), pp. 3914-3921, 2015. (in Chinese) https://doi.org/10.11817/j.issn.1672-7207.2015.10.047

[2] Luo, Z., Li, J., Jiang, Q., Zhang Y., Huang, Y., Assefa, E., Deng, H. "Effect of the Water-Rock Interaction on the Creep Mechanical Properties of the Sandstone Rock", Periodica Polytechnica Civil Engineering, 62(2), pp. 451-461, 2018. https://doi.org/10.3311/PPci.11788

[3] Zhou, G.-L., Xu, T., Zhu, W.-C., Chen, C.-F., Yang, T.-H. "A Time-Dependent Thermo-Mechanical Creep", Engineering Mechanics, 34(10), pp. 1-9, 2017. (in Chinese) https://doi.org/10.6052/j.issn.1000-4750.2016.05.0376
2. Normalized strength parameters both have negative correlations with creep damage variable and the residual strength has a sharper decline than the unloading amount of confining pressure. It shows that creep damage has significant effect on the failure strength and the ultimate failure degree of sandstone, respectively.

3. Based on the SEM and EDS tests, lithological characters of different samples are similar and some main features on failure surface of sandstone with different levels of creep damage can be found, such as pores, pits, cracks and scratches. However, there are facts that the diameter of pore is commonly larger than that of crack, the shapes of pores are irregular and the amounts of them are massive.

4. The creep damage has a significant effect on the mesoscopic structure of sandstone, but the porosity can't reflect it very well. Thus, some other pore parameters are proposed to describe this effect, and the average value of mean pore diameters is finally determined as the evaluation parameter. The agreement between the average value of mean pore diameters and creep damage variable demonstrates the rationality of the proposed parameter.

\section{Acknowledgement}

This work was supported by Key Laboratory of Geological Hazards on Three Gorges Reservoir Area (China Three Gorges University), Ministry of Education open fund project (No.2018KDZ14), the Natural Science Foundation of Hubei Province of China (No.2017CFB605), the National Natural Science Foundation of China (Nos. 51309142, 51439003).

[4] Fan, Q., Li, S., Gao, Y. "Experimental study on triaxial creep properties of soft rock", Chinese Journal of Rock Mechanics and Engineering, 26(7), pp. 1381-1385, 2007. [online] Available at: http://qikan.cqvip.com/Qikan/Article/Detwail?id=25633716 [Accessed: 05 June 2019] (in Chinese)

[5] Yang, Z.-W., Jin, A.-B., Zhou, Y., Yan, Q., Wang, K., Gao, Y.-J. "Parametric analysis of Burgers model and creep properties of rock with particle flow code", Rock and Soil Mechanics, 36(1), pp. 240-248, 2015. [online] Available at: http:/qikan.cqvip.com/ Qikan/Article/Detail?id=663341932 [Accessed: 30 August 2019] (in Chinese)

[6] Cundall, P. A., Strack, O. D. L. "A discrete numerical model for granular assemblies", Geotechnique, 29(1), pp. 47-65, 1979. https://doi.org/10.1680/geot.1979.29.1.47 
[7] Zhu, Q.-Y., Yin, Z.-Y., Hicher, P.-Y., Shen, S.-L. "Nonlinearity of one-dimensional creep characteristics of soft clays", Acta Geotechnica, 11(4), pp. 887-900, 2016.

https://doi.org/10.1007/s11440-015-0411-y

[8] Zhao, Y., Zhang, L., Wang, W., Wan, W., Li, S., Ma, W., Wang, Y. "Creep Behavior of Intact and Cracked Limestone Under MultiLevel Loading and Unloading Cycles", Rock Mechanics and Rock Engineering, 50(6), pp. 1409-1424, 2017. https://doi.org/10.1007/s00603-017-1187-1

[9] Haeberli, W., Hallet, B., Arenson, L., Elconin, R., Humlum, O., Kääb, A., Kaufmann, V., Ladanyi, B., Matsuoka, N., Springman, S., Mühll, D. V. "Permafrost Creep and Rock Glacier Dynamics", Permafrost and Periglacial Processes, 17(3), pp. 189-214, 2006. https://doi.org/10.1002/ppp.561

[10] Hilairet, N., Reynard, B., Wang, Y., Daniel, I., Merkel, S., Nishiyama, N., Petitgirard, S. "High-Pressure Creep of Serpentine, Interseismic Deformation, and Initiation of Subduction", Science, 318(5858), pp. 1910-1913, 2007. https://doi.org/10.1126/science.1148494

[11] Jiang, Q., Li, J., Luo, Z., Xu, X., Assefa, E., Deng, H. "Study on the Time-lag Failure of Sandstone With Different Degrees of Unloading Damage", Periodica Polytechnica Civil Engineering, 63(1), pp. 206-214, 2019. https://doi.org/10.3311/PPci.13260

[12] Zhao, G.-Y., Dai, B., Dong, L.-J., Yang, C. "Experimental research on mechanical characteristics and strength criterion of rock of triaxial unloading tests under different stress paths", Rock and Soil Mechanics, 36(11), pp. 3121-3147, 2015. (in Chinese) https://doi.org/10.16285/j.rsm.2015.11.011

[13] Li, D., Sun, Z., Xie, T., Li, X., Ranjith, P. G. "Energy evolution characteristics of hard rock during triaxial failure with different loading and unloading paths", Engineering Geology, 228, pp. 270 281, 2017.

https://doi.org/10.1016/j.enggeo.2017.08.006

[14] Liang, Y., Li, Q., Gu, Y., Zou, Q. "Mechanical and acoustic emission characteristics of rock: Effect of loading and unloading confining pressure at the postpeak stage", Journal of Natural Gas Science and Engineering, 44, pp. 54-64, 2017. https://doi.org/10.1016/j.jngse.2017.04.012

[15] Seifabad, M. C., Sadrnejad, S. A., Ebrahimi, D. "A Study of Swelling Behaviour in a Tunnel Using Finite Element Methods", Periodica Polytechnica Civil Engineering, 59(2), 103-107, 2015. https://doi.org/10.3311/PPci.7538

[16] Wang, K., Bilek, S. L. "Invited review paper: Fault creep caused by subduction of rough seafloor relief", Tectonophysics, 610, pp. 1-24, 2014.

https://doi.org/10.1016/j.tecto.2013.11.024

[17] Leoni, M., Karstunen, M., Vermeer, P. A. "Anisotropic creep model for soft soils", Géotechnique, 58(3), pp. 215-226, 2008. https://doi.org/10.1680/geot.2008.58.3.215

[18] Yin, Z.-Y., Chang, C. S. "Stress-dilatancy behavior for sand under loading and unloading conditions", International Journal for Numerical and Analytical Methods in Geomechanics, 37(8), pp. 855-870, 2011.

https://doi.org/10.1002/nag.1125
[19] Tao, M., Li, X., Wu, C. "Characteristics of the unloading process of rocks under high initial stress", Computers and Geotechnics, 45, pp. 83-92, 2012.

https://doi.org/10.1016/j.compgeo.2012.05.002

[20] Bennett, K. C., Berla, L. A., Nix, W. D., Borja, R. I. "Instrumented nanoindentation and 3D mechanistic modeling of a shale at multiple scales", Acta Geotechnica, 10(1), pp. 1-14, 2015.

https://doi.org/10.1007/s11440-014-0363-7

[21] Li, D., Wang, E., Kong, X., Jia, H., Wang, D., Ali, M. "Damage precursor of construction rocks under uniaxial cyclic loading tests analyzed by acoustic emission", Construction and Building Materials, 206, pp. 169-178, 2019.

https://doi.org/10.1016/j.conbuildmat.2019.02.074

[22] Weng, L., Wu, Z., Liu, Q. "Evaluating Damage and Microcracking Behavior of Granite Using NMR Testing under Different Levels of Unconfined Compression", International Journal of Geomechanics, 19(1), 2019.

https://doi.org/10.1061/(asce)gm.1943-5622.0001335

[23] Chen, C., Xu, T., Heap, M. J., Baud, P. "Influence of unloading and loading stress cycles on the creep behavior of Darley Dale Sandstone", International Journal of Rock Mechanics and Mining Sciences, 112, pp. 55-63, 2018. https://doi.org/10.1016/j.ijrmms.2018.09.002

[24] Aydan, Ö., Ito, T., Özbay, U., Kwasniewski, M., Shariar, K., Okuno, T., Özgenoğlu, A., Malan, D. F., Okada, T. "ISRM Suggested Methods for Determining the Creep Characteristics of Rock", Rock Mechanics and Rock Engineering, 47(1), pp. 275-290, 2014. https://doi.org/10.1007/s00603-013-0520-6

[25] Zhou, K.-P., Li, B., Li, J.-L., Deng, H.-W., Bin, F. "Microscopic damage and dynamic mechanical properties of rock under freezethaw environment", Transactions of Nonferrous Metals Society of China, 25(4), pp.1254-1261, 2015. https://doi.org/10.1016/S1003-6326(15)63723-2

[26] Lemaitre, J. "How to use damage mechanics", Nuclear Engineering and Design, 80(2), pp. 233-245, 1984. https://doi.org/10.1016/0029-5493(84)90169-9

[27] Zhang, Q., Yang, G., Ren, J. "New Study of Damage Variable and Constitutive Equation of Rock", Chinese Journal of Rock Mechanics and Engineering, 22(1), pp. 30-34, 2003. (in Chinese) [online] Available at: http://www.rockmech.org/CN/abstract/abstract22768. shtml [Accessed: 05 June 2019]

[28] Št’astná, A., Šachlová, Š., Pertold, Z., Přikryl, R. "Factors affecting alkali-reactivity of quartz-rich metamorphic rocks: Qualitative vs. quantitative microscopy", Engineering Geology, 187, pp. 1-9, 2015. https://doi.org/10.1016/j.enggeo.2014.12.012

[29] Chen, F., Zeng, L., Liang, F. "Quantitatively Determination of Chemical Compositions of Solid Exsolution Lamellae in Apatites from the Chinese Continental Drilling (CCSD) Project: An Application of Energy-Dispersive Spectroscopy (EDS) with SEM", Acta Geologica Sinica, 80(12), pp. 1930-1934, 2006. (in Chinese) https://doi.org/10.3321/j.issn:0001-5717.2006.12.016

[30] Otsu, N. "A Threshold Selection Method from Gray-Level Histograms", IEEE Transaction on Systems, Man, and Cybernetics, 9(1), pp. 62-66, 1979. https://doi.org/10.1109/TSMC.1979.4310076 
[31] Miao, D. "Study on processing method of SEM soil image based on MATLAB", Master's degree, Taiyuan University of Technology, 2014. (in Chinese)

https://doi.org/10.7666/d.Y2692917

[32] Jiu, B., Huang, W., He, M., Lv, C., Liang, F. "Quantitative Analysis of Micron-Scale and Nano-Scale Pore Throat Characteristics of Tight Sandstone Using Matlab", Applied Sciences, 8(8), pp. 12721287, 2018

https://doi.org/10.3390/app8081272
[33] Xu, R.-Q., Deng, Y., Xu, B., Lai, J., Zhan, X., Xu, L., Lu, J. "Calculation of Three-Dimensional Porosity of Soft Soil Based on SEM Image", Chinese Journal of Rock Mechanics and Engineering, 34(7), pp. 1497-1502, 2015. [online] Available at: http:/qikan.cqvip.com/ Qikan/Article/Detail?id=89837688504849534855485051[Accessed: 30 August 2019] (in Chinese) 